\title{
The Adsorption Study of Copper Removal by Chitosan-Coated Sludge Derived from Water Treatment Plant
}

\author{
Meng-Wei Wan, Chan-Ching Wang, and Chien-Min Chen
}

\begin{abstract}
The rapid development of science and technology in recent years created a standard of living that caused serious deterioration in the environment. Heavy metal contamination in the soil, surface water and groundwater is one of the major environmental problems due to their non-biodegradability and toxicity. Thus, how to solve efficiently the heavy metal pollution in groundwater has become the most essential issue around the world. Commercialized adsorbents such as activated carbon are effective in removing heavy metals but remain costly. In this study, the removal of copper (II) from aqueous solutions using a biodegradable material, known as chitosan coated sludge (CCS), was investigated under static conditions. The sludge was obtained from a water treatment plant. Moreover, batch experiments were conducted to investigate the adsorption effect under different initial concentration $\left(C_{0}=100,500,1000\right.$ and $2000 \mathrm{mg} / \mathrm{L})$, solution at $\mathrm{pH}=3$ to $\mathrm{pH}=4$ and contact time $(0.5,1,2$, $4,6,12$ and $24 \mathrm{~h}$ ). Results indicated that the data fitted well with Langmuir model at $Q_{\max }$ value of $18.83 \mathrm{mg} / \mathrm{g}$ CCS for $\mathrm{Cu}(\mathrm{II})$ ions at two hours contact time. The kinetic data best fit the pseudo-second order equation, indicating that chemisorption is the rate-limiting step of the $\mathrm{Cu}(\mathrm{II})$ adsorption.
\end{abstract}

Index Terms-Adsorption, chitosan, copper, sludge, water treatment plant.

\section{INTRODUCTION}

Due to dramatic development of industry, heavy metal pollution has become a global environmental consideration. Heavy metals, such as cadmium, chromium, cobalt, copper, nickel and mercury are common water pollutants [1]. These metals exist in aqueous waste from industries, such as mining, metal plating, and electronics [2]. On the other hand, the presence of heavy metal ions in industrial effluents and drinking water resources is also relevant due to their toxicological properties and potential impacts on human health and environment [3].Thus, efficient solution to heavy metal pollution in groundwater has become the most essential issue around the world.

Copper $(\mathrm{Cu})$, in particular, is a natural element predominantly used in production industry applications. Copper is also a very common substance that occurs

Manuscript received April 20, 2013, revised June 18, 2013. This work was supported by the Taiwan National Science Council (NSC 99-2221-E-041-017).

Meng-Wei Wan and Chien-Min Chen are with the Department of Environmental Engineering and Science, Chia Nan University of Pharmacy and Science, Tainan City 71710 Taiwan (e-mail:peterwan @mail.chna.edu.tw; jimchen@mail.chna.edu.tw)

Chan-Ching Wang is with the Department of Environmental Engineering, National Kaohsiung Marine University, 142 Haijhuan Road, Nanzih District, Kaohsiung 81157, Taiwan (email: stacy13306@gmail.com). intrinsically in the environment and spreads through natural phenomena. It is extensively utilized by electrical industries, in fungicides and in antifouling paints. It is toxic to humans, producing oxidative stress when ingested at high concentrations [4]. Among the ionic species of copper, $\mathrm{Cu}$ (II) ions can have alarming effects in aqueous solution, attaching easily to organic and inorganic matter based on solution $\mathrm{pH}$ [5].

Application of biopolymers such as chitin and chitosan is one of the emerging adsorption methods for the removal of dyes and heavy metal ions, even at low concentrations [6]. Chitosan, a biopolymer prepared through the deacetylation of chitin, which is the major component of crustaceans shells and the second most abundant biopolymer in nature, has been widely used for adsorption of heavy metal ions [7]-[10]. Its chelating properties are attributed to the amino and hydroxyl groups in chitosan chain, that therefore, can act as chelation sites for different metals [11].

The sludge which is found in the bottom of a sedimentation tank in water treatment plants is primarily composed of water. The solids in the sludge are mainly flocs, excess coagulant, such as alum. Alum sludge has a solids concentration of only about $1 \%$ when automatically removed from the basin, or about $2 \%$ if manually removed. Many options exist for disposal of sedimentation sludge such as disposal in streams, lagoons and landfills.

Applying permeable reactive barrier for the recovery of metals is a practically environmental remediation technology by building filters along a contaminated stream of groundwater. The remediation of the contaminated waste stream would be costly when chitosan is used alone because construction of filters along the stream requires large quantities of adsorbents. Immobilizing chitosan with a low-cost material results to a lesser amount of chitosan used without affecting the overall metal adsorption capacity [12]. Unfortunately, there are limited references to adsorption studies that provide readily available support for chitosan in spite of its inherent practical advantages.

In this research, the application of an appropriate immobilization material is essential for the utilization of chitosan in industrial applications. Providing a support material (sludge) for the immobilization of chitosan is considered to be both an economical and practical method, which can further enhance its metal binding capacity. The aim of this study is to investigate the removal of heavy metals using chitosan coated sludge (CCS) derived from a water treatment plant. The batch adsorption experimental data were 
used to determine the effectiveness of CCS to uptake copper ions individually from solutions.

\section{MAterials AND METHODOLOGY}

\section{A. Chemicals and Reagents}

Chitosan (low molecular weight, CAS No. 9012-76-4) was purchased from Sigma-Aldrich; anhydrous $\mathrm{CuSO} 4 ; \mathrm{HCl}$, fuming 37\%; NaOH; ICP Standard Solution, $1000 \mathrm{mg} / \mathrm{L}$ $\mathrm{Cu}(\mathrm{II})$ were supplied from Merck Company and Sand (EM Science, Gibbstown, NJ). Deionized (DI) water of milli-Q purity was used for all reagent solutions.

\section{B. Preparation of CCS}

Immobilization of the chitosan was similar to the methods found in the literature [12] with only slight modifications. About $5 \mathrm{~g}$ of chitosan and $100 \mathrm{~g}$ of dry sludge were stirred in $300 \mathrm{~mL}$ of $5 \%(\mathrm{v} / \mathrm{v}) \mathrm{HCl}$ for $5 \mathrm{~h} .1 \mathrm{~N} \mathrm{NaOH}$ was added drop by drop until neutralization occurred. The adsorbent was allowed to settle, washed with DI water and was oven-dried for $24 \mathrm{~h}$ at $65{ }^{\circ} \mathrm{C}$. After drying and grinding, the materials were sieved, passed through Mesh No. $25(0.700 \mathrm{~mm})$ and collected on Mesh No. $35(0.500 \mathrm{~mm})$. The homogenous particle size of $0.500 \mathrm{~mm}$ which illustrated the best adsorption efficiency based on previous optimization study of adsorbent's particle size for $\mathrm{Cu}$ adsorption was used in the entire experiments. The new adsorbent is called chitosan-coated sludge(CCS).

\section{Characteristic Analysis}

SEM photographs were taken with a HITACHI S-3000N Scanning Microscope to examine the morphology and surface structure of the adsorbents at the required magnification at room temperature. Thermal gravimetric analyses (TGA) were performed on freezedried sludge, chitosan and chitosan-coated sludge (CCS) samples using Rigaku Thermo Plus TG 8120 in the temperature range of 30 $-800^{\circ} \mathrm{C}$ at a heating rate of $10^{\circ} \mathrm{C}$ per minute. Surface area of the adsorbents was measured by the single point BET (Brunauer, Emmett and Teller) method using the Accelerated Surface Area and Porosimetry System (Micromeritics, ASAP 2010).

\section{Elemental Analysis by ICP-OES}

A Perkin Elmer 2000DV Inductively Coupled Plasma-Optical Emission Spectrometer (ICP-OES) was used for quantitative determination of metal ion concentration. Standard solutions for the instrument's calibration curve were prepared as indicated: $10 \mathrm{~mL}$ of $1000 \mathrm{mg} / \mathrm{L}$ of ICP standard diluted to $100 \mathrm{~mL}$ with DI water which served as stock solution. Subsequently, different volumes of the stock solution $(0.05,0.1,0.5,1.0,2.0,4.0,6.0$ and $10.0 \mathrm{~mL})$ were pipetted into $100 \mathrm{~mL}$ volumetric flasks and diluted to mark.

\section{E. Batch Adsorption Studies}

The adsorption of $\mathrm{Cu}(\mathrm{II})$ ions were analyzed in a batch system at room temperature with varied concentrations ranging from $100-2000 \mathrm{mg} / \mathrm{L}$.

\section{1) Single metal ions experiment}

The experiments were performed using single solutions of the adsorbates maintained at $\mathrm{pH}$ 4.5. The solutions were prepared in DI water using the anhydrous CuSO4. Thirty $\mathrm{mL}$ of single metal ion solution was placed in $100-\mathrm{mL}$ Erlenmeyer flasks and was then combined with $2.5 \mathrm{~g}$ of CCS. The equilibration (shaking) time was $24 \mathrm{~h}$ at a static speed of $50 \mathrm{rpm}$. After equilibrium, the solution was filtered using Whatman \#40 filter papers. A Whatman \#40 filter was selected as a clean-up filter in preparation for ICPOES analysis. The filtrate was analyzed with ICP-OES. The amount of $\mathrm{Cu}(\mathrm{II})$ ions adsorbed per unit mass of CCS was calculated using the equation:

$$
Q_{0}=\frac{\left(C_{0}-C e\right) V}{m}
$$

where $C_{o}$ and $C_{e}$ are the initial and equilibrium concentrations of metal ion solution $(\mathrm{mg} / \mathrm{L})$, respectively; $\mathrm{V}$ is the volume of the solution in liter $(\mathrm{L})$; and $\mathrm{m}$ is the amount of $\mathrm{CCS}$ in $\operatorname{grams}(\mathrm{g})$. The percentage adsorption was determined using the equation:

$$
\text { Percentage adsorption }(\%)=\frac{\left(C_{0}-C e\right) 100}{C_{0}}
$$

where $C_{o}$ and $C_{e}$ are the initial and equilibrium concentration of metal ion solution $(\mathrm{mg} / \mathrm{L})$.

\section{EFFECT OF $\mathrm{C}_{\mathrm{O}}$ AND CONTACT TIME}

In this study, the initial concentration and contact time are two main parameters in the adsorption of $\mathrm{Cu}$ (II) ions in aqueous solution. This study determined the capacity of CCS for removing $\mathrm{Cu}(\mathrm{II})$ ions in the solution at the equilibrium time. The Co concentration were 100, 500, 1000 and 2000 $\mathrm{mg} / \mathrm{L}$ prepared by diluting the stock solution of $\mathrm{Cu}$ (II) ions. The contact times were varied from $0.5,1,2,4,6,12$ and 24 h.

\section{A. Effect of Solution $p H$}

The $\mathrm{C}_{\mathrm{o}}$ of $100 \mathrm{mg} / \mathrm{L}$ was adjusted to the required $\mathrm{pH}$ value using $1 \mathrm{~N} \mathrm{HCl}$ and $1 \mathrm{~N} \mathrm{NaOH}$. CCS (2.5 g)were equilibrated at the desired $\mathrm{pH}$ of the specified volume of the adsorbates $(30 \mathrm{~mL})$ for $24 \mathrm{~h}$ at a static speed of $50 \mathrm{rpm}$. The final $\mathrm{pH}$ of the filtrate was determined and its metal ion content was analyzed using ICP-OES.

\section{B. Kinetics of Adsorption}

In order to investigate the controlling mechanism of the adsorption processes, pseudo first-order and pseudo second-order kinetics were applied in the data. This includes the mass transfer and chemical reactions due to the large number and variation of different chemical groups on chitosan chains [13].

\section{1) Pseudo first-order kinetics}

The pseudo first-order kinetics can be expressed as:

$$
\log \left(q_{e}-q_{t}\right)=\log \left(q_{e}\right)-\frac{k_{1}}{2.303} t
$$

where $k_{l}$ is the rate constant of pseudo first-order adsorption 
$\left(\min ^{-1}\right) ; \mathrm{q}_{\mathrm{e}}$ and $\mathrm{q}_{\mathrm{t}}$ are the amount of metal ion adsorbed per gram of chitosan-coated sludge (mg/g CCS) at equilibrium and at any time $t$, respectively. A straight line for the plot of $\log \left(\mathrm{q}_{\mathrm{e}}-\mathrm{q}_{\mathrm{t}}\right)$ versus $\mathrm{t}$ would give the first-order rate constant $\mathrm{k}_{1}$ and equilibrium adsorption capacity $\mathrm{q}_{\mathrm{e}}$, from the slope and the intercept of the line.

\section{2) Pseudo second-order kinetics}

The pseudo second-order kinetics can be expressed as:

$$
\frac{t}{q_{t}}=\frac{1}{k_{2} q_{e}^{2}}+\frac{1}{q_{e}} t
$$

where $k_{2}(\mathrm{~g} / \mathrm{mg} \mathrm{min})$ is the rate constant of pseudo second-order adsorption. The plot of $\mathrm{t} / q_{t}$ versus $\mathrm{t}$ would give the pseudo second-order rate constant $k_{2}$ and $q_{e}$. The pseudo second-order kinetic model is based on the assumption that the rate-limiting factor maybe chemisorption involving valence forces through sharing of electrons between the amino group and metal ions [14].

\section{Equilibrium Isotherms Studies}

Adsorption isotherm models describe the relationship between adsorbates and adsorbents at equilibrium. The two most wellknown isotherm models are the Langmuir and the Freundlich. In this study, equilibrium isotherms were used to determine the adsorption mechanism of CCS for $\mathrm{Cu}$ (II) ions. The adsorbents were combined with fixed volumes $(30 \mathrm{~mL})$ of metal ion solutions varying the initial concentrations (100, 500,1000 , and $2000 \mathrm{mg} / \mathrm{L}$ ) at $4 \mathrm{~h}$ contact time. The relation between the amount of adsorbed metal and the remaining concentration of metal ions in solution is described by the isotherm studies.

\section{1) Langmuir isotherm model}

The Langmuir equation, which is valid for monolayer adsorption onto a surface with a finite number of identical sites, can be expressed as:

$$
Q_{0}=\frac{Q_{\text {max }} k_{L} C_{e}}{1+b C_{e}}
$$

where $Q_{\max }(\mathrm{mg} / \mathrm{g})$ is the maximum amount of the metal ion per unit weight of CCS capable of forming complete monolayer coverage on the surface, bound at a high equilibrium concentrations $C_{e} ; Q_{o}$ is the amount of metal ion adsorbed per unit weight of CCS at equilibrium; $\mathrm{k}_{\mathrm{L}}$ and $\mathrm{b}$ are the Langmuir constants, where $b$ is related to the affinity of binding sites [15]. According to the Langmuir equation, the maximum adsorption capacity was derived from the following equation:

$$
Q_{\max }=\frac{k_{L}}{b}
$$

where $k_{L}$ and $\mathrm{b}$ can be determined from the linear plot of $1 / \mathrm{Q}_{0}$ against $1 / C_{e}$.

\section{2) Freundlich isotherm model}

Another widely used empirical equation, the Freundlich equation, was based on adsorption on a heterogeneous surface. The equation is represented by:

$$
Q_{0}=k_{f} C_{e}^{n}
$$

where $k_{f}$ is roughly an indicator of the adsorption capacity and $1 / \mathrm{n}$ of the adsorption intensity. A linear form of the Freundlich equation will yield the constant $\mathrm{k}_{\mathrm{f}}$ and $1 / \mathrm{n}$.

$$
\ln Q_{0}=\ln k_{f}+\frac{1}{n} C_{e}
$$

Therefore, $k_{f}$ and $1 / \mathrm{n}$ can be determined from the linear plot of $\ln Q_{o}$ versus $\ln C_{e}$. The magnitude of the exponent 1/n gives an indication of the favorability of adsorption. The obtained values of $n>1$ signify favorable adsorption conditions [15].

\section{RESUlt AND Discussion}

\section{A. Characteristic Analysis}

Sludge, chitosan and CCS bioadsorbents were characterized and among these three, the CCS illustrates higher surface area and pore volume when compared to the other two adsorbents. Obviously the metal uptake capacity of this adsorbent is higher due to its free adsorption sites. SEM/EDS analysis was exploited to illustrate the variation of morphology, mineralogical and chemical composition for each adsorbent.

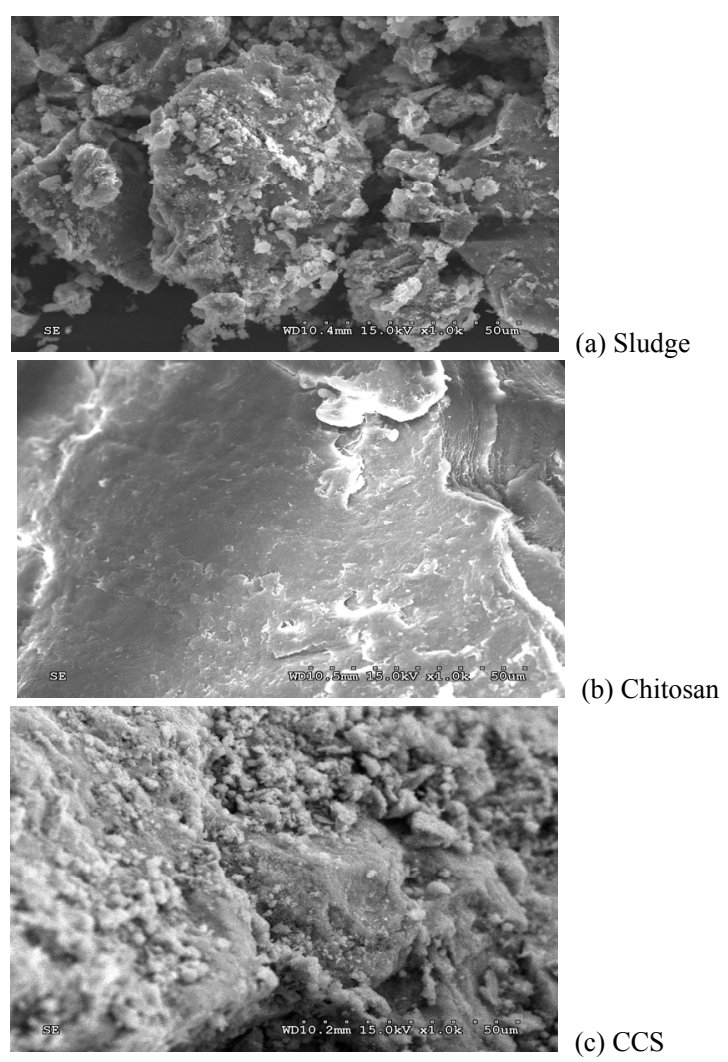

Fig. 1. SEM pictures of different adsorbents

The SEM images of the surface on sludge, chitosan and CCS are shown in Fig. 1. Fig. 1(a) and 1(b) indicates that sludge displays a rough structure on surface with a large surface area while chitosan displays a relative smooth structure on surface with a lesser surface area. Fig. 1(c) confirmed the presence of many pores and some cracks on 
the surface of the CCS adsorbent.

\section{B. Batch Adsorption Experiment}

\section{1) Effect of Co and contact time}

As shown in Fig. 2, it is remarkable that an increase in the initial concentration $(\mathrm{Co})$ for both $\mathrm{Cu}$ (II) ions led to an increase in the adsorption capacity of chitosan-coated sludge (CCS) at various contact times. This can be attributed to the mass transfer effects and the driving force of the concentration gradient being directly proportional to the initial concentrations. Fig. 3 demonstrated that the higher adsorption rates were examined at the beginning. The plateau values indicated that the adsorption equilibrium was gradually attained. Retention of $\mathrm{Cu}(\mathrm{II})$ ion was noted to be inversely related to $C_{o}$. At the lowest $(100 \mathrm{mg} / \mathrm{L})$ and the lower $(100 \sim 500 \mathrm{mg} / \mathrm{L})$ concentrations, the equilibrium adsorption capacities were related to the ionic size. At the higher Co $(1000 \sim 2000 \mathrm{mg} / \mathrm{L})$, the equilibrium adsorption capacities were attributed to the hardness of the metal ions.

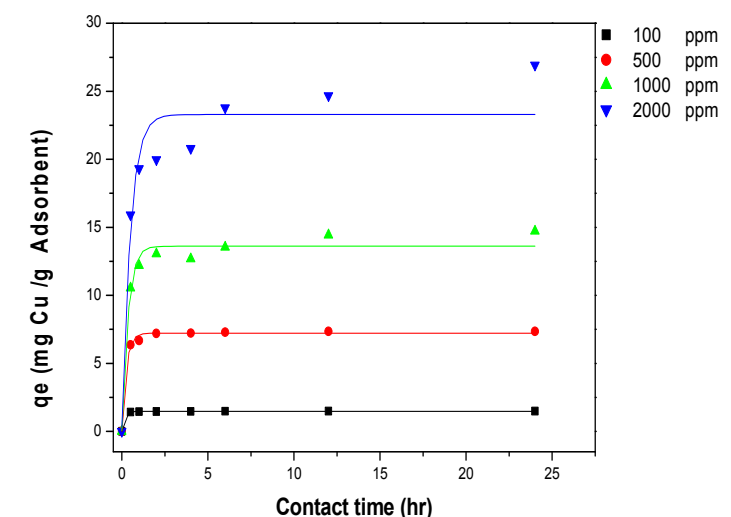

Fig. 2. Effect of initial concentration and contact time on equilibrium adsorption of $\mathrm{Cu}$ (II) ions onto chitosan-coated sludge.

Masel (1996) expounded that hardness is inversely related to the ability of the molecule to share electrons [16]. It follows that when the hardness is small, and the number of shared electrons will be large and vice versa. Therefore, more numbers of electrons were shared, which resulted in stronger covalent interactions with the chitosan at a higher Co. In this case, the maximum adsorption capacity was achieved after the binding ability of the adsorbent approached saturation at equilibrium time.

As shown in Fig. 3, an exposure time of $24 \mathrm{~h}$ was used during batch studies to achieve the equilibrium. It demonstrated that CCS can potentially remove more than $50 \%$ of $\mathrm{Cu}$ (II) ions at the highest concentration and reached the equilibrium at $1 \mathrm{~h}$ regardless of the initial concentrations $\left(\mathrm{C}_{\mathrm{o}}\right)$. Moreover, when adsorbate concentrations were raised, binding capacity of the adsorbent reached saturation instantaneously, which resulted in diminishing the overall \% adsorption of $\mathrm{Cu}$ ions.

\section{2) Effect of $p H$}

To prevent precipitation, experiments were carried out at $p H<6$ to ensure the solubility of metal ions [14], [17], [18]. At high $\mathrm{pH}$, precipitation usually occurred with the metallic ions attached to hydroxide ions forming $\mathrm{Cu}(\mathrm{OH})_{2}$ at $p H>8$.

To clarify the influence of solution $\mathrm{pH}$ on the adsorption capacity, chitosan-coated sludge (CCS) was subjected to different $\mathrm{pH}$ values $(\mathrm{pH}=2,3,4)$ at an oscillating time of 1 hour. The choice of the oscillating time was in accordance to CCS adsorption equilibrium experiments. The results of experiments are shown in Figure 4. The CCS illustrates good adsorption phenomena at $\mathrm{pH} 4$ and $\mathrm{pH} 3$. However, it demonstrated the downward trend as the $\mathrm{pH}$ value decline.

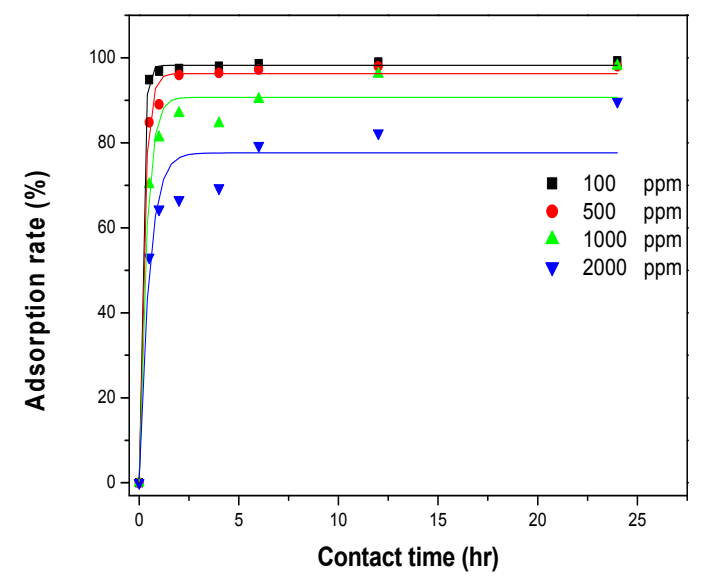

Fig. 3. Adsorption percentage at different concentrations and contact time of $\mathrm{Cu}$ (II) ion onto chitosan-coated sludge.

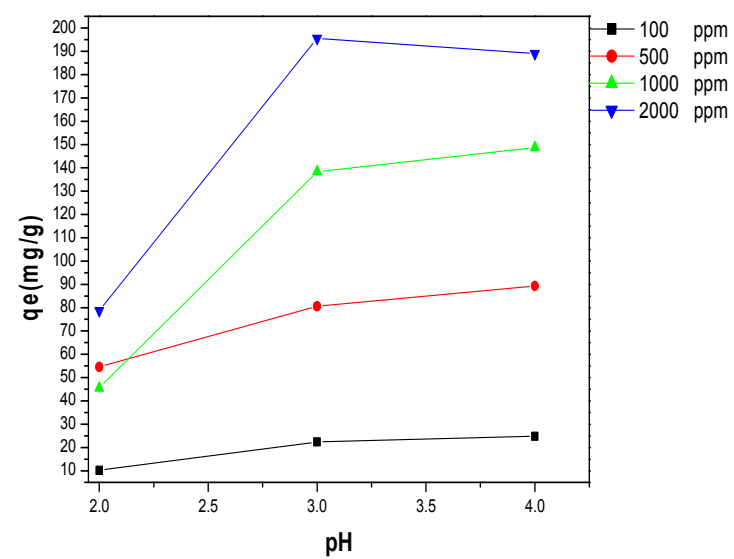

Fig. 4. The $\mathrm{pH}$ effect of CCS on equilibrium adsorption

The CCS adsorption capacity is influenced significantly by the $\mathrm{pH}$ value. The chitosan attached to the water treatment plant sludge provides larger contact surface resulting to an increase in adsorption capacity. However, in acidic condition, there is competition between $\mathrm{H}^{+}$ions and the heavy metals in terms of binding with the basic $\mathrm{NH}_{2}$ groups of chitosan. Metal adsorption percentage decreased since most of the $\mathrm{NH}_{2}$ groups of CCS are in the protonated form $\left(\mathrm{NH}_{3}{ }^{+}\right)$[19].

Taboada et al., (2003) and Wan et al. (2010) described the similar phenomena as the following competing reactions, where $\mathrm{M}^{2+}$ represents the divalent metal ion and $\mathrm{R}$ is the polymer structure of chitosan [19], [20].

$$
\mathrm{M}^{2+}+\mathrm{RNH}_{2} \rightarrow \mathrm{M}\left(\mathrm{RNH}_{2}\right)^{2+}
$$

The amino group of chitosan may react with hydrogen ions $\left(\mathrm{H}^{+}\right)$according to:

$$
\mathrm{H}^{+}+\mathrm{RNH}_{2} \rightarrow \mathrm{H}\left(\mathrm{RNH}_{2}\right)^{+}
$$

Conversely, there was an improvement in the metal adsorption percentage while the $\mathrm{pH}$ value was increased. CCS exhibited enough binding capacity. The adsorption percentage of different $\mathrm{Cu}$ (II) concentrations increased with 
$\mathrm{pH}$ range from 2 to 4 . However, the influence on retention time was minimal for the succeeding values $(\mathrm{pH} 3-4)$ regardless of contact time. This effect suggested that the amino group was deprotonated. The chelation mechanism outranked the adsorption one where more metal ions chelating with chitosan.

\section{Kinetics of Adsorption}

To investigate the controlling mechanism of the adsorption processes, pseudo first-order and pseudo second-order kinetic equations were both examined. Table I shows the adsorption kinetic studies of $\mathrm{Cu}$ (II) ions onto $\mathrm{CCS}$ at different $\mathrm{C}_{\mathrm{o}}$. The pseudo first-order kinetic model did not adequately describe the adsorption results with a low correlation coefficient for the entire data $(0.1855-0.6038)$. However, the pseudo second-order kinetic model provided an impressive and comparable correlation for the adsorption of both ions in contrast to the pseudo first-order model (0.9977-0.9998).

The pseudo first-order rate model has been widely used for sorption of metals [14], which was widely used for reversible reactions with an equilibrium being established between liquid and solid phases. In many cases, the pseudo first order do not fit well to the whole range of contact time and is generally applicable over the initial stage of adsorption process [21].

TABLE I: ADSORPTION KINETIC STUDIES OF CU (II) IONS ONTO CHITOSAN-COATED SLUDGE (CCS)

\begin{tabular}{|c|c|c|c|c|c|c|c|}
\hline \multirow{2}{*}{$\mathrm{Cu}(\mathrm{II})\left(\mathrm{C}_{0}, \mathrm{ppm}\right)$} & \multicolumn{3}{|c|}{ Pseudo-first order kinetic model } & \multicolumn{4}{|c|}{ Pseudo-second order kinetic model } \\
\hline & $\mathrm{k}_{1}$ & $\mathrm{q}_{\mathrm{e}}$ & $\mathrm{R}^{2}$ & $\mathrm{q}_{\mathrm{e}}$ & $\mathrm{q}^{2}$ & $\mathrm{k}_{2}$ & $\mathrm{R}^{2}$ \\
\hline 100 & 0.00005 & 2.08 & 0.1855 & 1.49 & 2.23 & 0.26588 & 0.9998 \\
\hline 500 & 0.00005 & 6.95 & 0.309 & 7.37 & 54.39 & 0.03043 & 0.9996 \\
\hline 1000 & 0.00016 & 11.81 & 0.5439 & 14.90 & 222.10 & 0.00289 & 0.9995 \\
\hline 2000 & 0.00023 & 16.81 & 0.6038 & 273.97 & 75060.99 & 0.00001 & 0.9977 \\
\hline
\end{tabular}

Ho (2006) illustrated that the pseudo second-order reaction was used to distinguish the kinetic equation based on the concentration of a solution from the adsorption capacity of a solid [22]. In this study, the rate constant $\mathrm{k}_{2}$ was determined experimentally by plotting the slopes and intercepts of $t / q t$ against $t$. The high correlation coefficient shown in Table I illustrated an agreement of experimental data with the pseudo second-order kinetic model (Eq. (4)) for different $\mathrm{Cu}$ (II) ion concentrations. The overall adsorption rate for both ions appeared to be controlled by the chemical process. This conclusion is based on the assumption that chemisorption involved sharing or exchange of electrons as covalent forces between the transition metal cations and adsorbent and ion exchange [22].

Based on the equation, the adsorption rate $\mathrm{dq} / \mathrm{dt}$ is proportional to the second-order of (qe-q). High adsorption equilibrium capacity, $\mathrm{q}_{\mathrm{e}}$, results in fast adsorption rates and short equilibrium times. Short equilibrium times coupled with high adsorption capacity indicates a high degree of affinity between $\mathrm{Cu}(\mathrm{II})$ ions and CCS. Moreover, several studies for adsorption of divalent metals on heterogeneous sorbents reported that the majority of the metal sorption kinetics follows the pseudo second-order mechanism [22].

\section{Adsorption Isotherm}

The experimental adsorption data were examined by using the Langmuir and Freundlich isotherm model to indicate the possible adsorption mechanism. In this study, the regression coefficients were selected to indicate good linearity, which confirmed that the $\mathrm{Cu}(\mathrm{II})$ ions followed the two theories of adsorption, as shown in Table II. The results show that at different equilibrium time, the calculated data of Langmuir isotherm which exhibited the highest regression correlation for both ions ( $>98 \%$ ) described a better fitting model than that of Freundlich isotherm, the $\mathrm{R}^{2}$ value can be higher than 0.99 .

Langmuir isotherm model is most suitable for monolayer adsorption based on the assumption of finite numbers of adsorption sites. All sites are equivalent and there is no interaction between adsorbed ions. The result indicates the applicability of monolayer coverage on the surface of CCS in spite of the surface modification [19]. Moreover, the maximum adsorption capacities of $\mathrm{Cu}$ (II) ions were obtained bu using Langmuir isotherm model, which are 11.88, 12.56, $18.83,16.50,16.61,17.45$, and $17.54(\mathrm{mg}-\mathrm{Cu} / \mathrm{g}-\mathrm{CCS})$ at different times $(0.5,1,2,4,6,12$, and 24 hours) respectively. This results also indicate that CCS reached the saturated adsorption after 2 hours, where the maximum amount of the adsorption is $18.83 \mathrm{mg} / \mathrm{g}$. A single copper layer ions are adsorbed (uniform monolayer adsorption) for each active site. The adsorbent presents many adsorption active sites (repeating amine group), each with the same pro-active position forcing the adsorption of copper ions from the solution. However, longer adsorption time resulted to a slight desorption of copper ions. This phenomenon is caused by the water purification sludge itself which contains some metal elements desorbing into the solution forming positively charged ion resulting into competitive adsorption of $\mathrm{Cu}$ (II) ions.

No value of the CCS calculated by the Freundlich isotherm model is greater than 1 , which reveals the phenomena of favorable metal adsorption. Thus, CCS adsorbent illustrated high adsorption potential for heavy metal removal in aqueous solution. 
TABLE II: SUMMARY OF ADSORPTION ISOTHERMS STUDIES FOR CU(II) IONS ONTO CHITOSAN-COATED SLUDGE (CCS)

\begin{tabular}{cccccccc}
\hline \hline \multirow{2}{*}{$\begin{array}{c}\text { Contact } \\
\text { time (hrs) }\end{array}$} & \multicolumn{4}{c}{ Langmuir isotherm } & \multicolumn{3}{c}{ Freundlich isotherm } \\
\cline { 2 - 8 } & $\mathrm{K}_{\mathrm{L}}$ & $\mathrm{B}$ & $\begin{array}{c}\mathrm{Q}_{\max } \\
(\mathrm{mg} / \mathrm{g})\end{array}$ & $\mathrm{R}^{2}$ & $\mathrm{n}$ & $\mathrm{K}_{\mathrm{F}}$ & $\mathrm{R}^{2}$ \\
\hline 0.5 & 0.29 & 0.025 & 11.88 & 0.9957 & 2.08 & 0.6636 & 0.9846 \\
\hline 1 & 0.49 & 0.039 & 12.56 & 0.9964 & 2.14 & 0.8972 & 0.9776 \\
\hline 2 & 0.58 & 0.031 & 18.83 & 0.9994 & 2.06 & 1.1293 & 0.9379 \\
\hline 4 & 0.75 & 0.045 & 16.50 & 0.9992 & 2.23 & 1.3110 & 0.9325 \\
\hline 6 & 1.10 & 0.066 & 16.61 & 0.9987 & 2.14 & 1.5025 & 0.9512 \\
\hline 12 & 1.58 & 0.091 & 17.45 & 0.9983 & 2.15 & 1.9099 & 0.9265 \\
\hline 24 & 2.32 & 0.132 & 17.54 & 0.9928 & 1.92 & 2.1498 & 0.9470 \\
\hline \hline
\end{tabular}

\section{CONCLUSION}

Bioadsorbent, chitosan-coated sludge (CCS), has demonstrated high efficiency in removing $\mathrm{Cu}(\mathrm{II})$ ions from aqueous solution. The amount of $\mathrm{Cu}$ (II) ions adsorbed increased with increasing $\mathrm{pH}$. The equilibrium studies were described using both Langmuir and Freundlich isotherm models. The Langmuir isotherm illustrated the best description of the metal adsorption mechanism. The maximum adsorption capacity of Cu (II) ions was $18.83 \mathrm{mg} / \mathrm{g}$ after 2 hours contact time. Moreover, the equilibrium kinetics agreed well with pseudo second-order kinetics, which indicated that the adsorption was controlled by chemisorption.

This study has illustrated the possible adsorption behavior of CCS to remove copper ions from water. In conclusion, these preliminary results indicate the possibility of using sludge derived from water treatment plant to establish an inexpensive large-scale filter as a permeable reactive barrier for metal removal, the goal of waste recycle and reuse.

\section{APPENDIX}

$b \quad$ Langmuir constant, related to the energy or the net enthalpy of adsorption process

$C_{e} \quad$ equilibrium concentration, $\mathrm{mg} / \mathrm{L}$

$C_{o} \quad$ initial concentration, $\mathrm{mg} / \mathrm{L}$

$K_{f} \quad$ Freundlich constant, an indicator of adsorption capacity

$K_{L} \quad$ Langmuir constant incorporating the enthalpy of adsorption

$k_{1} \quad$ rate constant of pseudo-first order, $\min ^{-1}$

$k_{2} \quad$ rate constant of pseudo-second order, $\mathrm{g} / \mathrm{mg} \min$

$n \quad$ Freundlich constant

$q_{e} \& q_{t}$ amount of metal adsorbed at equilibrium and at any time, $\mathrm{mg} / \mathrm{g}$

$Q_{\max }$ maximum capacity or "Langmuir" monolayer sorption capacity, $\mathrm{mg} / \mathrm{g}$

$Q_{o} \quad$ amount of metal ion adsorbed, $\mathrm{mg} / \mathrm{g}$

$t \quad$ time, $\min$

$v \quad$ volume of the solution, $\mathrm{L}$

\section{REFERENCES}

[1] M. Sprynskyy, B. Buszewski, A. P. Terzyk, and J. Namieśnik, "Study of the selection mechanism of heavy metal $\left(\mathrm{Pb}^{2+}, \mathrm{Cu}^{2+}, \mathrm{Ni}^{2+}\right.$, and $\left.\mathrm{Cd}^{2+}\right)$ adsorption on clinoptilolite," Journal of Colloid Interface Science, vol. 304, pp. 21-28, 2006.
[2] Elsayed-Ali, T. Abdel-Fattah, and H. E. Elsayed-Ali, "Copper cation removal in an electrokinetic cell containing zeolite," Journal of Hazardous Materials, vol. 185, pp. 1550-1557, 2011.

[3] F. Fu and Q. Wang, "Removal of heavy metal ions from wastewaters: a review," Journal of Environmental Management, vol. 92, pp. 407-418, 2011.

[4] R. Schmuhl, H. M. Krieg, and K. Keizer, "Adsorption of Cu (II) and $\mathrm{Cr}(\mathrm{IV})$ ions by chitosan: Kinetics and equilibrium studies," Water SA, vol. 27, pp. 1-7, 2001.

[5] S. Hasan, T. K. Ghosh, D. S. Viswanath, and V. M. Boddu, "Dispersion of chitosan on perlite for enhancement of copper (II) adsorption capacity," Journal of Hazardous Materials, vol. 152, pp. 826-837, 2008.

[6] G. Crini, "Non-conventional low-cost adsorbents for dye removal: A review," Bioresource Technology, vol. 97, pp. 1061-1085, 2006.

[7] E. Guibal, "Interactions of metal ions with chitosan-based sorbents: a review," Separation and Purification Technology, vol. 38, pp. 43-74, 2004.

[8] R. S. Vieira and M. M. Beppu, "Mercury ion recovery using natural and crosslinked chitosan membranes," Adsorption, pp. 11, 731-736, 2005.

[9] R. S. Vieira and M. M. Beppu, "Interaction of natural and crosslinked chitosan membranes with $\mathrm{Hg}$ (II) ions," Colloids Surface A, vol. 279, pp. 196-207, 2006.

[10] R. S. Vieira and M. M. Beppu, "Dynamic and static adsorption and desorption of $\mathrm{Hg}(\mathrm{II})$ ions on chitosan membranes and spheres," Water Research, vol. 40, pp. 1726-1734, 2006.

[11] R. Bassi, S. O. Prasher, and B. K. Simpson, "Removal of selected metal ionsfrom aqueous solutions using chitosan flakes," Separation. Science Technology, vol. 35, pp. 547-560, 2000.

[12] M. W. Wan, I. G. Petrisor, H. T. Lai, D. Kim, and T. F. Yen, “Copper adsorption through chitosan immobilized on sand to demonstrate the feasibility for in situ decontamination," Carbohydrate Polymers, vol. 55 , pp. 249 - 254, 2004.

[13] G. Annadurai, L. Y. Ling, and J. F. Lee, "Adsorption of reactive dye from an aqueous solution by chitosan: Isotherm, kinetic and thermodynamic analysis," Journal of Hazardous Materials, vol. 152, pp. 337 - 346, 2008.

[14] Y. Săg and Y. Aktay, "Removal of nickel from aqueous solutions using crab shells," Journal of Hazardous Materials, vol. B125, pp. 201 - 204 , 2002.

[15] V. M. Boddu, K. Abburi, J. L. Talbott, and E. D. Smith, "Removal of hexavalent chromium from wastewater using a new composite chitosan biosorbent," Environmental Science \& Technology, vol. 37, pp. 4449 - 4456, 2003.

[16] R. I. Masel, "Principles of adsorption and reaction on solid surfaces," Wiley-IEEE, pp. 143, 1996.

[17] K. G. Bhattacharyya and S. S. Gupta, "Kaolinite, montmorillionite, and their modified derivatives as adsorbents for removal of $\mathrm{Cu}$ (II) from aqueous solution," Separation and Purification Technology, vol. 50, pp. 388 - 397, 2006.

[18] A. T. Paulino, M. R. Guilherme, A. V. Reis, E. B. Tambourgi, J. Nozaki, and E. C. Muniz, "Capacity of adsorption of $\mathrm{Pb}^{2+}$ and $\mathrm{Ni}^{2+}$ from aqueous solutions by chitosan produced from silkworm chrysalides in different degrees of deacetylation," Journal of Hazardous Materials, vol. 147, pp. 139 - 147, 2007.

[19] M. W. Wan, C. C. Kan, B. D. Rogel, and M. P. Dalida, "Adsorption of Copper (II) and Lead (II) ions from Aqueous Solution on Chitosan-Coated Sand," Carbohydrate Polymers, vol. 80, pp. 891-899, 2010 . 
[20] E. Taboada, G. Cabrera, and G. Cardenas, "Retention capacity of chitosan for copper and mercury ions," Journal of the Chilean Chemical Society, vol. 48, version on-line, 2003.

[21] Y. S. Ho and C. McKay, "Kinetic model for Lead (II) sorption on to peat," Adsorption Science and Technology, vol. 16, pp. $243-255$, 1998.

[22] Y. Ho, "Review of second-order models for adsorption systems," Journal of Hazardous Materials," vol. B136, pp. 681-689, 2006.

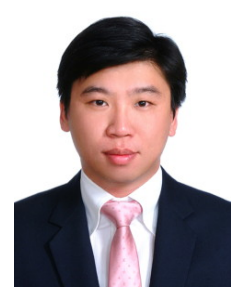

Meng-Wei Wan was born at Tainan City, Taiwan in 1974. He received his B.S. degree in Environmental Science, Tunghai University, Taichung, Taiwan from 1992 - 1996. He received his M.S. degree from department of Civil and Environmental Engineering, University of Southern California, USA from 19992001. Finally, He received his Ph.D. from department of Civil and Environmental Engineering, University of Southern California, USA from 1999- 2001.

He is now associate professor of Environmental Engineering and Sciences at College of Sustainable Environment in Chia Nan University of Pharmacy and Science, Tainan City Taiwan. His research interests have focused mostly in the field of water pollution control using green technologies, and the development of clean energy technology. His research endeavor has extended to various environmental issues in their sustainable applications, including developments of microbial polymers, ultrasound chemistry applied to environmental problems, and developments of a portable, modular unit for sulfur removal in fuel cell system.

Dr. Wan awarded total 2 gold medals and 2 silver medals at the 2012 64th and 2011 63th IENA Nuremberg - International Trade Fair Ideas-Inventions - New Products, Nürnberg, Germany. He also awarded total 2 gold medals, 1 silver medal and 1 bronze medal at the 2011 and 2012 Taipei International Invention Show \& Technomart, Taipei, Taiwan.

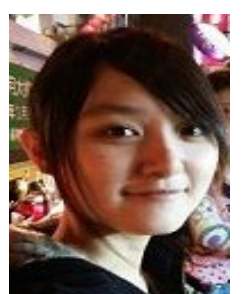

Chan-Ching Wang was born at Yunlin County, Taiwan on 1990/02/03. She received his B.S. degree in Environmental Engineering and Sciences, Chia Nan University of Pharmacy and Science, Tainan, Taiwan from $2008.09-2012.06$. She is now a M.S. student at department of Marine Environmental Engineering, National Kaohsiung Marine University, Kaohsiung City, Taiwan.

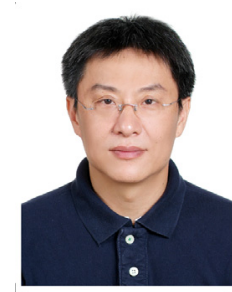

Chien Min Chen is a professor in the Department of Environmental Resources and Management, Chia Nan University of Pharmacy and Science, Tainan, Taiwan. He is currently the dean of the College of Sustainable Environment. He earned his PhD degree from Rutgers University, New Jersey, USA, in 1994, and specialized in aquatic toxicology, especially in endocrine disrupting chemicals. He is one of few researchers in Taiwan using fish, especially Japanese medaka, and some aquatic invertebrates as biomonitoring species for water pollution. He currently works on the effects of wastewater, either from industrial or domestic origin, on induction of vitellogenin in Japanese medaka and the impact of such discharges at the ecological level. He is not only the first investigator using multimedia human risk assessment tools to evaluate the impact of dioxins from municipal waste incinerators in Taiwan, but also the first person who conducted ecological risk assessment on a hazardous waste landfill in Taiwan. The results were published in an international journal. He also actively participates in different POPs' issues at the national level. Not only focusing on environmental toxicology, Prof Chen also collaborate with colleagues working on different fields in wastewater treatment process applying different technologies, such as constructed wetland, MBR and absorption. He also owns five patents personally related to green technology. 